\title{
Editorial
}

\section{Vida cara e insegura}

El costo de la vida y la delincuencia organizada aparecen en las encuestas del Institulo de Opinión Publica de la UCA como dos grandes problemas sociales sobre el telón de londo de la militarización persistente y del modelo económico antisocial. Con loda razón nos hacemos la pregunla: acuerdos de paz o recuerdos de la paz? A medida que avanzamos sobre el segundo semestre del año ciertos grupos influyentes hacen los mayores esluerzos por relegar al olvido los acuerdos de paz, especialmente el proceso pactado de desmilitarización y las recomendaciones élico-jurídicas de la Comisión de la Verdad. La consigna de perdón y olvido se está transtormando en olvido del perdón y en cegar la memoria de un pasado de impunidad.

Con ocasión de la fiesta del soldado, altos miembros de la cúpula militar allá presentes, y también presentes en el intorme de la Comisión de la Verdad, se hicieron acreedores del reconocimiento general por su comporlamiento " francamente encomiable" y su colaboración al proceso de paz en la mesa de negociaciones. El reconocimiento se hizo acompanar del más normal de los retiros con unas anormales jubilaciones. Algunas semanas después los Ministros de Defensa del IsImo autoevaluaron que los ejércitos no pueden reducir su actual tamaño por razones de seguridad interna nacional. No es ésta la tesis popular, en el sentido más amplio de apreciación ciudadana, que ve en los presupuestos mililares y en sus partidas secretas el gasto más gravoso, improductivo y gestador de corrupción que pesa sobre estas pobres y endeudadas naciones.

La ironía del año preelectoral es que se están politizando las reser- 
vas de armas escondidas o no declaradas al mismo liempo que se echa el velo del olvido sobre la cronologla de la violencia que gesló el uso de dichas armas y que se prolonga en la temible delincuencia y en la lundada presencia de los escuadrones de la muerte. No vamos a repelir que la desdichada historia de los buzones de armas ha mermado la confiabilidad de grupos inlegrantes del FMNL como pesado gravamen en el próximo proceso electoral. Pero lo que resulta éticamente insoportable es que se alcen como los más puritanos fiscales aquellos miembros del partido y gobierno que apresurada y minorilariamente forzaron la ley de amnistía. Esto es ver la mota de polvo en el ojo ajeno y ocultar la viga del ojo propio. Cómo se explica una delincuencia que utiliza armas pesadas y granadas del ejército, que roba y cambia placas de los carros y los traslada de pais a país, o que, del parecer de la ONUSAL, testimonia la presencia de escuadrones de la muerte?. Constitucional o no conslitucional, la presencia vigilante del ejército en el campo y el asentamiento de un cuerpo de la armada americana no ha recibido el beneplácito de la mayoría popular, aunque algunos transportistas confien en dicha protección. El historial del ejército, sobre todo cuerpos de seguridad, ha socavado la confiabilidad que el pueblo pueda lener en ellos y se resiste a seguir pagando unos onerosas impuestos para cubrir la exagerada partida de delensa-seguridad.

Pareceria, y asi se dijo en reciente programa televisado, A FONDO, que el gobierno no empena las medidas más eticientes para controlar la delincuencia con la oculta intención de justificar la presencia militar on campos y carreteras de la nación. Las preguntas no carecen de razón : por qué la policia nacional civil no se transfiere de las zonas ex-conflictivas a las zonas, hoy por hoy, más conflictivas? Por qué no se les dola del equipo, vehículos y presupuesto no lan eficazmente utilizado en otras instituciones de defensa y seguridad?

Por supuesto que el llajelo de la delincuencia no se reduce a menos armas y más policias civiles porque tiene raices económicas (desempleo y desadaptación profesional), raices de resentimiento y venganza y lambién raices culturales y psicológicas. Por esta razón ha sido un gran error político, cívico y ético querer cegar el intorme de la Comisión de la Verdad con la precipilada ley de perdón y olvido. La cronología de la violencia ha marcado las conciencias y la conducta de quienes ejercieron impunemente la pena de muerte. Al negarse a cumplir con las recomendaciones pacladas, miembros o exmiembros del ejército o cuerpos de seguridad, al igual que la administración de justicia, no han cobrado conciencia de los errores cometidos. Se imposibilita el proceso de reeducación civil. Conviene recordar que el informe de la Comisión de la Verdad lo redaclaron, en equipo, los tres miembros propuestos por la 
ONU y aceptados por el gobiemo; pero quien hizo el informe fue el pueblo declarante, los más de 20.000 testimonios que dijeron la verdad. Ahora nos toca a todos los miembros de la sociedad ( tamilia, coleglosuniversidades, iglesias, asociaciones sindicales y palronales, partidos y administración pública... ) rescatar los mejores valores y crilerios civicos, lo cual es más lento y diff́cil que asfaltar carreteras. Sin embargo el gobierno puede hacer más lenlo este proceso si propicia la persistente militarización . La operación quirúrgica es dificil, pero es necesaria; hasta el momento, con aciertos y tropiezos, el FMNL está dando mejor ejemplo. Al fin y al cabo, el error y la mentira se hizo sobre "armas escondidas tuera o bajo tierra". La delincuencia trabaja con armas de aqul y de origen sospechoso y lo hace a la luz del sol.

Con las repetidas acusaciones y revelaciones sobre las armas escondidas del FMNL y sus conexiones lerroristas (léase ETA) el gobierno olvida sus más prolongadas conexiones con el anterior gobiemo de los EE.UU., que le nutrió con muchas más armas morliferas, le adoctrinó con sus asesores de la muerte y le entrenó los escuadrones ad-hoc durante doce anos. Estas atrocidades no se convierten en hechos éticos por la simple razón de que se planitican entre gobiernos oficialmente reconocidos. Son más bien los hechos los que testimonian de la eticidad de los gobiernos. Por otra parte, este olvido del pasado y estas acusaciones del presenle siven como cortinas de humo para distraer del problema económico-social gestado por el modelo neoliberal.

Es aleccionador que CENITEC en su "propuesla de un programa económico-social de consenso para El Salvador", introduzca el manejo de la política macroeconómica con la premisa del "cumplimiento salisfaclorio de los acuerdos de paz". Se Irata de una visión económicosocial de dichos acuerdos." Las implicaciones de este supuesto en términos de la viabilidad de nuestra propuesta son de suma importancia. En primer lugar, signitica que la crisis política tenderá a superarse y, por tanto, que el país contará en los próximos anos con un clima de estabilidad política y social mínimo que coadyuvará favorablemente al establecimienlo de un ambiente adecuado para la inversión privada, tanio nacional como extranjera. En segundo lugar, significa que el pais seguirá contando , si bien con una tendencia decreciente, con el apoyo financiero y técnico de la comunidad internacional en los esluerzos de la reconsinucción nacional. En tercer lugar, significa que la asignación del gaslo público y la nueva inversión en infraeslructura social serán determinadas de manera creciente por consideraciones económicas y sociales y que será posible reorientar progresivamente el gasto militar hacia los gaslos sociales"... (Economia Política; No.17; p. 26) 
En páginas anteriores , con el título de "las frágiles bases del actual programa económico", sostiene lo que la mayoria, menos uno, afirma en sus encuestas abiertas: "el déficit del desarrollo social." En cuanlo al segundo desafio, es decir a la necesidad de construir nuevos equilibrios distributivos que permitan superar en un tiempo razonable tos graves problemas sociales y de concentración del ingreso en el pals, el déficit del actual programa económico es aún mayor, ya que prácticamente se ha carecido de una estrategia para entrentarlo. Como ha sido sefialado repelidas veces, el aclual programa no ha sido acompanado de una política social integral y complementaria a la estralegia economica. Resulta revelador en tal sentido comprobar que el gasto social y el salario minimo real solamente han experimentado incrementos marginales. (Grálicos 5 y 6).

La debilidad del programa gubernamental en la parte social se debe a la visión del "derrame" que subyace en la propuesta global. Según esta visión, los objetivos del crecimiento y la distribución son incompatibles en el corto plazo, razón por la cual se planlea la necesidad de buscar primero el crecimiento y sólo después enfrentar el problema de la distribución. Dicho de otro modo, esla visión parte de la premisa de que los benelicios del crecimiento se derramarán aulomáticamente desde los estralos de mayores ingresos hacia los estratos de menores ingresos de la población. Con esa visión no puede sorprender que el programa económico no contemple mecanismos institucionales que permitan la distribución equilativa del excedente y que, por el contrario, el resultado de la política general y de las políticas específicas como la de la privatización de la banca, haya sido una mayor concentración del ingreso y de la riqueza"... (lbidem; pp. 9-10)

CENITEC Iraduce lécnicamente el senlimiento ciudadano manilestado en repetidas encuestas y entrevistas. El pasado mes de junio el Instituto Universitario de Opinión Pública-UCA sondea la opinión de los salvadorefios sobre el proceso electoral. La encuesla parece indicar que la población se mueve enlre la esperanza y la desilusión. Un $80 \%$ afirma su intención de votar, aunque un $25 \%$ de este grupo no poseen, de momento, su carnet elecloral. La indecisión popular se Iraduce en que un $51,1 \%$ de quienes desean votar dicen no tener un partido de preferencia - y casi una tercera parte de la misma población juzga que ningún partido es capaz de luchar contra los problemas de la pobreza, del respeto y delensa de los Derechos Humanos.

A algunos secretarios y precandidatos de los partidos políticos les interesa más la cota de apreciación tributada por los encuestados y si su nombre sube o baja como corcho que flola en el termómetro de la opj- 
nión pública. A ellos y a nosotros debieran preocuparnos más los problemas develados en las encuestas. El problema número uno es el deterioro económico-social, en sus variados componentes: allo costo de la vida $(30,3 \%)$; la falta de empleo $(15,3 \%)$; la pobreza-injusticia social $(15,3 \%)$; los problemas de salud-educación (3,5\%). Sumando porcenlajes, un $64 \%$ de los volos hace del deterioro económico el problema número uno. Pero no sólo de pan malvive el hombre; al coslo de la vida se anade la inseguridad de seguir viviendo; la delincuencia y las drogas aparecen como el segundo problema en la acumulación de volos. (IUDOP; Boletin, No.3; p.5...)

Estos dalos son tanto más fehacientes por cuanto muestran una opinión permanente. En la encuesta pasada por el IUDOP en octubre de 1992 se reagrupan en orden similar los principales problemas del El Salvador. "La pobreza, desempleo y bajos salarios $(47,1 \%)$; la crisis económica y social $(40,7 \%)$; la inflación, alto costo de la vida $(25,8 \%)$; la ley del IVA $(10,1 \%)$; la delincuencia $(22,2 \%)$; el proceso de paz, la postguerra, la reconciliación nacional $(16,2 \%)$." En este entorno del oclubre1992 el 83,1\% opinaba que la siluación económica estaba igual o peor que antes de los acuerdos de paz; y la milad de los encuestados $(49,7 \%)$ se adelanlaba a decir que estaria peor dentro de un ano, opinión avalada por la reciente encuesla (junio-1993) anles citada, (IUDOP; Boletín, No. I, 1992 p. 3). Todos estos datos, truto de la opinión pública, retroalimentan los breves párrafos exlraclados del programa de consenso económico-social propuesto por CENITEC.

Hemos titulado este editorial "Vida cara e insegura" apegados al sentimiento ciudadano. En el mes de julio-1993 de nuevo el IUDOP recaba la opinión pública sobre la Comisión de la Verdad, a la que dedicamos la Editorial del No. 32 (La verdad os hará libres). Por su extensión no es lectura fácil, ni por su contenido es leclura agradable el Informe de la Comisión de la Verdad; como dijo el Dr. Francisco Lima, las lágrimas sallan a los ojos. Si las cúpulas del partido-gobierno quisieron desprestigiarlo hasta el calilicativo de estupidez, "el $45 \%$ de los salvadorenos están satislechos con el informe presenlado por la Comisión de la Verdad, mientras que un $28 \%$ están insatisfechos, y otro porcentaje igual prefiere no opinar" ( IUDOP, Boletín No. 2, 1993)

Detallando un poco más la razón del volo casi la milad de quienes se muestran conformes $(46,5 \%)$ piensa que el conlenido del informe es 10 que realmente pasó; el $58 \%$ de las personas satislechas atirma que el informe presentó a los responsables y divulgó lo que no se sabia. También es interesante analizar las razones expresadas por el $28 \%$ insatisfechos con el informe: no menciona algunos crimenes $(39,7 \%)$; falta 
investigar, es superticial ( $15 \%$ ); esluvo más de un lado que del otro $(8,4 \%)$; es mentiroso $(8,4 \%)$. Cuál es la base histórica de estos argumentos? Cuando en sólo seis meses de intenso Irabajo la Comisión de la Verdad devela toda una cronología de la violencia y en un muestreo ampliamente representativo analiza con el mayor detalle treinta casos de atrocidades personales o comunitarias, cuando basa sus investigaciones "en pruebas abnumadoras, sustanciales y suficienles", fundadas en más de $\mathbf{2 0 . 0 0 0}$ declaraciones populares, enmarcado lodo ello en los prolocolos del Derecho Inlernacional firmados por nuestro país, y cuando en doce anos nuesiro órgano oficial judicial no habia avanzado más allá de la promesa "se harán invesligaciones exhaustivas", no son verdaderas razones las emilidas por el minorilario grupo de los inconformes. Hay un detalle iluminador: los votos de quienes apoyan el inlorme se concentran en el medio obrero marginal, en el sector social medio-bajo y en el área rural. Los insatisfechos se siluaan en el grupo social medio-alto del área urbana. "Dime con quién andas y te diré quién eres": la dirigencia de ARENA no anda con el pueblo que ha sulrido más con la cronologia de la violencia y con la impunidad de sus autores.

El reverso concuerda con el anverso: $55,5 \%$ de la población encuestada está en conlra de la Ley de Amnislia. La razón es que debe haber justicia y que los culpables deben ser casligados. El pasado siguen siendo presente: casi la mitad $(46,17 \%)$ de este grupo afirma que la impunidad no ha terminado. De cara al fuluro, tres de cada cuatro entrevistados $(78,7 \%)$ se muestran a favor de remover de sus cargos a los funcionarios que han violado los derechos humanos. Casi dos tercios de la población encuestada (63\%) piensa que al pueblo salvadoreno se le ha enganado de lorma masiva en asuntos de violación de los derechos humanos. En los sectores altos de la sociedad salvadoreha se ubica el $30 \%$ tavorable a la ley de amnistla; razón, la imporlancia del perdónolvido para la reconciliación, y porque toda persona tiene derecho a otra oportunidad. Por desgracia, la historia nos muestra que la otra oportunidad es la corrupción y la delincuencia organizada; no han cambiado ni las conciencias ni las conductas.

Hemos definido la inflación como una guerra civil monetaria con el arma de los precios. La guerra duró doce anos y la inllación ya cumplió los veinle. Estos tenómenos, más que coyunturales, han nıodelado nuestras conductos de agresividad política y económica. El modelo neoliberal ha generado hasta el momento el "derrame de la desigualdad" y la delincuencia organizada multiplica la inseguridad. La población desea cambiar para mejorar, pero las lentitudes del tribunal electoral dificulta su derecho a votar, y las controversias de los partidos políticos su derecho a elegir. Aún nos queda medio ano para acudir a las urnas y elegir un 
luluro que no sea prolongación del presente y del pasado. La propaganda prepolente nos quiere hacer olvidar el pasado de la violencia impune y el presente de la economia antisocial. La solución no lloverá desde arriba, a imagen de unas elecciones que se harán en la época seca. Todas las fuerzas sociales debemos develar la verdad del pasado-presente y pasar de la prolesta a la propuesta de las nuevas soluciones que ya comienzan a delinearse. 